\title{
High expression of the p53 isoform $\gamma$ is associated with reduced progression-free survival in uterine serous carcinoma
}

\author{
Katharina Bischof ${ }^{1,2^{*}}$ (D), Stian Knappskog ${ }^{3,4}$, Ingunn Stefansson ${ }^{5,6}$, Emmet Martin McCormack ${ }^{1}$, Jone Trovik ${ }^{7,2}$, \\ Henrica Maria Johanna Werner ${ }^{7,2}$, Kathrine Woie ${ }^{2}$, Bjorn Tore Gjertsen ${ }^{1,8}$ and Line Bjorge ${ }^{1,2}$
}

\begin{abstract}
Background: Uterine serous carcinoma (USC) is a rare but aggressive subtype of endometrial carcinoma. Largescale comprehensive efforts have resulted in an improved molecular understanding of its pathogenesis, and the p53 pathway has been proposed as a key player and is potentially targetable. Here we attempt to further portray the p53 pathway in USC by assessing p53 isoform expression.
\end{abstract}

Methods: We applied quantitative Real-Time PCRs (RT-qPCR) for expression analyses of total p53 mRNA as well as quantitative distinction of $\mathrm{p} 53 \beta, \mathrm{p} 53 \gamma$, and the total mRNA of amino-terminal truncated $\Delta 40 \mathrm{p} 53$ and $\Delta 133 \mathrm{p} 53$ in a retrospective cohort of 37 patients with USC. TP53 mutation status was assessed by targeted massive parallel sequencing. Findings were correlated with clinical data.

Results: The p53 isoform expression landscape in USCs was heterogeneous and dominated by total $\Delta 133$ p53, while the distinct $p 53 \beta$ and $p 53 \gamma$ variants were found at much lower levels. The isoform expression profiles varied between samples, while their expression was independent of TP53 mutation status. We found high relative p53y expression to be associated with reduced progression-free survival (PFS).

Conclusions: This is the first indication that elevated p53y expression is associated with reduced PFS in USC. This singlecenter study may offer some insight in the landscape of p53 isoform expression in USC, but further validation studies are crucial to understand the context-dependent and tissue-specific role of the p53 isoform network in gynecological cancer.

Keywords: Uterine serous carcinoma, Type II endometrial cancer, p53 isoforms, RT-qPCR, mRNA expression analysis, Biomarker

\section{Background}

Endometrial cancer is the most common gynecological malignancy in the Western world $[1,2]$, with the incidence increasing in recent years [3]. Traditionally, endometrial neoplasms are categorized into Type I and Type II cancers [4]. While the majority of tumors are classified as Type I, which are usually highly differentiated and thus less aggressive, around $20 \%$ of patients suffer from clinically aggressive Type II cancers that in a much higher percentage have extrauterine spread at the time

\footnotetext{
* Correspondence: katharina.bischof@uib.no

${ }^{1}$ Centre for Cancer Biomarkers (CCBIO), Department of Clinical Science,

Precision Oncology Research Group, University of Bergen, Bergen, Norway

2Department of Gynecology and Obstetrics, Haukeland University Hospital,

N-5021 Bergen, Norway

Full list of author information is available at the end of the article
}

of diagnosis and account for the majority of cancer related deaths [4-6].

Through large-scale comprehensive molecular characterization, endometrial carcinomas have recently been classified into four specific subgroups and we have gained a new understanding of the biology of USC [7]. The serous subtype has been shown to molecularly resemble basal-like breast cancers as well as high-grade serous ovarian carcinomas [7]. In USC, somatic mutations in the TP53 gene are a common characteristic and seen in more than $90 \%$ of cases, resulting in genetic instability and widespread copy-number alterations. Although other subtype-specific molecular features are present, including increased transcriptional activity of genes such as $C C N E 1$ or $M Y C$, that are involved in cell cycle regulation

(c) The Author(s). 2018 Open Access This article is distributed under the terms of the Creative Commons Attribution 4.0 International License (http://creativecommons.org/licenses/by/4.0/), which permits unrestricted use, distribution, and reproduction in any medium, provided you give appropriate credit to the original author(s) and the source, provide a link to the Creative Commons license, and indicate if changes were made. The Creative Commons Public Domain Dedication waiver (http://creativecommons.org/publicdomain/zero/1.0/) applies to the data made available in this article, unless otherwise stated. 
[7], it has become increasingly clear that the p53 pathway may be a key player in the genesis of USCs [8].

Mutant p53 proteins have been shown not only to lose their tumor-suppressive functions but also to gain oncogenic traits [9] Additionally, p53 function has recently been shown to be modulated by a number of alternative mechanisms through a network of structurally similar proteins in the p53 pathway [10, 11]. In TP53 wild-type USC, inactivation of the p53 pathway must occur through alternative cellular mechanisms.

High-throughput RNA sequencing has produced vast amounts of data showing that more than $90 \%$ of human protein-coding genes produce multiple mRNA isoforms through such posttranscriptional mechanisms as non-canonical splicing and the use of alternative promoters [12, 13]. In humans, at least 12 different protein-encoding transcripts from the TP53 locus have been reported; these are suggested to contain detectable, predictive, and prognostic markers to guide patient treatment in a large number of cancers [14]. The complex isoform composition limits the ability to quantitatively distinguish the amino-terminally truncated variants $\Delta 40 \mathrm{p} 53$ and $\Delta 133 \mathrm{p} 53$ into $\alpha, \beta$, and $\gamma$. For the carboxy-terminal (C-terminal) altered variants $\mathrm{p} 53 \beta$ and $\mathrm{p} 53 \gamma$ and the amino-terminally $(\mathrm{N}$-terminally) truncated isoforms $\Delta 40 \mathrm{p} 53$ and $\Delta 133 \mathrm{p} 53$, mRNA expression levels have been shown to be associated with tumor characteristics and aggressiveness in other p53-disrupted malignancies, such as breast cancer and epithelial ovarian carcinoma among others [11, 15-23].

In acute myeloid leukemia (AML), TP53 mutation represents a rare event. In this context, p $53 \beta$ and p $53 \gamma$ protein isoforms have been shown to positively correlate with the NPM1 mutation marker for survival, overall survival and response to chemotherapy. [24] Thus, the highly abrogated p53 pathway may represent an attractive future therapeutic target $[25,26]$.

While the functional roles of p53 isoforms have been studied in the past both in vitro and in a number of clinical studies, to the best of our knowledge, a characterization of p53 isoform expression in USC tissue has never been reported. In this study, we present the mRNA expression analysis of the main p53 isoforms (the exon composition of relevant p53 isoforms is illustrated in Fig. 1b) in combination with TP53 mutational status in serous endometrial cancers. Although the field of p53 research is constantly producing new insights into p53 structure and function, we are the first to offer an overview of the p53 isoform expression profiles of the main p53 isoforms in combination with TP53 mutational status in serous endometrial cancers.

\section{Methods}

\section{Patient characteristics and tumor specimens}

Between June 2001 and April 2013, a total of 79 women were diagnosed with and treated for USC at Haukeland

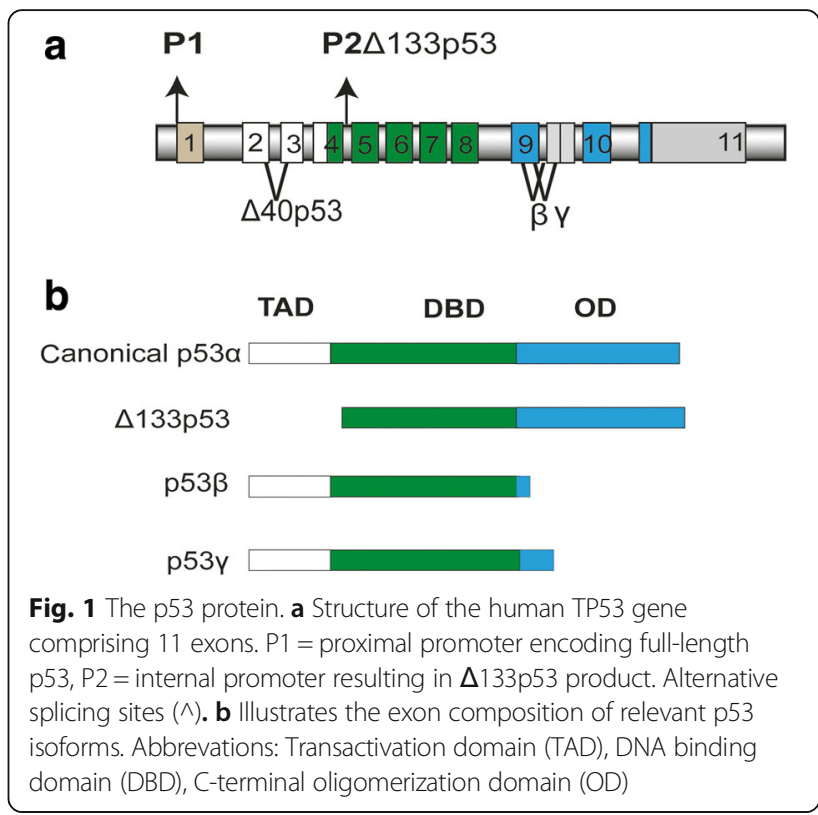

University Hospital, Bergen, Norway. For 37 of the patients, biological material for DNA sequencing and mRNA expression analysis was available together with prospectively collected clinicopathological data. The following parameters from our clinical database were relevant in this study: age at primary treatment, FIGO 2009 stage, level of complete cytoreduction and progression-free survival (PFS). PFS was defined as time in months from the last day of primary treatment to disease recurrence defined by RECIST criteria [27] Women were followed for a mean of 35 months (range 2-113), with the last follow-up entry in April 2015.

Tumor samples were acquired from hysterectomy specimens or diagnostic biopsies and included in the Bergen Gynecologic Cancer Biobank (REK Vest: Reference ID: 2014/1907). After collection at the time of primary diagnosis, tumor tissue was immediately frozen in liquid nitrogen. The tumor content of fresh frozen specimens was assessed in ethanol-fixed and hematoxylinand eosin-stained sections. While the minimum cutoff for inclusion was set to $50 \%$, tumor purity was above $80 \%$ in the majority of tissue samples studied. The histopathological analysis was performed at the Haukeland University Hospital, Department of Pathology. Specimens were fixed in buffered formaldehyde, embedded in paraffin and further processed in the laboratory before standard histological sections were made. Trained gynecologic pathologists performed the diagnostic assessments. This material has been reviewed previously [28].

\section{Nucleic acid isolation and CDNA synthesis}

DNA was isolated by tissue digestion overnight at $65^{\circ} \mathrm{C}$ in lysis buffer containing $\mathrm{NaCl}$, EDTA $0.5 \mathrm{M} \mathrm{pH} 8.5$, 
TrisM pH 8, sodium dodecyl sulfate (SDS) 5\%, proteinase $\mathrm{K} 20 \mathrm{mg} / \mathrm{ml}$ and $\mathrm{H}_{2} \mathrm{O}$, followed by standard ethanol precipitation with sodium perchlorate and isopropanol. DNA quantity was determined using a Qubit Fluorometer (Thermo Fisher Scientific, Waltham, MA, United States of America). RNA was extracted using the RNeasy Mini Kit (Qiagen, Hilden, Germany) according to the manufacturer's instructions and quantified using a NanoDrop M-1000 Spectrophotometer (Thermo Fisher Scientific, Waltham, MA, United States of America) and Agilent 2100 Bioanalyzer (Agilent Technologies, Santa Clara, CA, United States of America). Single-strand cDNA was synthesized from $500 \mathrm{ng}$ total RNA in a $20 \mu \mathrm{L}$ reaction mix, using the Transcriptor reverse transcriptase system (Roche, Basel, Switzerland) according to the manufacturer's protocol.

\section{Quantitative real-time PCR}

Quantitative PCRs (qPCR) were performed using specific primers and hydrolysis probes targeting TP53 on a LightCycler 480 instrument (Roche, Basel, Switzerland). Reaction mixes were prepared using the LightCycler 480 ProbesMaster kit (Roche, Basel, Switzerland), according to the manufacturer's instructions. Relative mRNA expression levels of the p53 transcripts were normalized to an internal reference, RPLP2 gene expression, amplified together with the p53 amplifications in a two-color duplex reaction. Primers/probes for detection of total p53, and mRNAs with the characteristic breakpoints for p53 $\beta, p 53 \gamma, \triangle 40$ p53 and $\triangle 133$ p53, as well as RPLP2 are listed in Additional file 1: Table S1; they were designed to be used under the same conditions in the qPCR amplification. All individual assays were validated on control DNA (plasmids) containing the specific isoform breakpoints and tested for cross-reactions against the other isoforms. Given this design, our assays for $\Delta 40 \mathrm{p} 53$, $\Delta 133 p 53$ yielded data representing the total pool of molecules harboring these breakpoints, including both the canonical $\mathrm{p} 53 \alpha$ and the $\mathrm{p} 53 \beta$ and $\mathrm{p} 53 \gamma$ forms in the

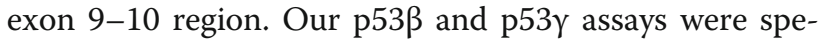
cific for these breakpoints and included the different $\mathrm{N}$-terminal isoforms. Thermocycling conditions for the qPCR were an initial denaturation step at $95{ }^{\circ} \mathrm{C}$ for $5 \mathrm{~min}$, followed by 50 cycles of denaturation for $10 \mathrm{~s}$ at $95{ }^{\circ} \mathrm{C}$ and annealing / elongation at $53{ }^{\circ} \mathrm{C}$ for $20 \mathrm{~s}$. Comparison between samples was performed using the $\Delta \Delta \mathrm{Ct}$-method. Each analysis was performed in triplicate.

\section{TP53 mutation calling}

TP53 mutation status was extracted from targeted massive parallel sequencing of tumor DNA. A total of $1000 \mathrm{ng}$ of dsDNA was fragmented using the Covaris ${ }^{\circ}$ M220 Focused-ultrasonicator ${ }^{\mathrm{Tm}}$ (Covaris, Woburn, MA, United States of America). Library preparation was performed using the Agilent SureSelect XT-kit (Agilent Technologies, Santa Clara, CA, United States of America). All samples were run on a MiSeq instrument (Illumina, San Diego, CA, United States of America), and preliminary mutation calling was performed using the MiSeq reporter (MSR) software. From the raw mutation calling output, post-processing filters were applied and all suspected TP53 mutations were validated by manual inspection of sequencing reads using the Integrative Genomics Viewer [29].

\section{Statistical analyses}

The Shapiro-Wilk test was applied to assess the normality assumption. As the distribution of total p53, $\Delta 40 \mathrm{p} 53$, $\Delta 133 p 53, p 53 \beta$ and $p 53 \gamma$ was non-Gaussian, Spearman correlation was calculated for continuous variables and Mann-Whitney $U$ test was used to identify correlations between continuous data (age, PFS, FIGO stage and isoform expression levels) and TP53 mutation status, presence of complete cytoreduction or age grouped by median. Fisher's exact test was used for comparisons of categorical variables (patient age, presence of complete cytoreduction and mutation status). Multiple linear regression was used to assess whether confounding was present. Survival analyses were performed by the Kaplan-Meier method, and subsets of patients (divided by median relative expression of isoforms) were compared using the log-rank test. All $p$-values are two sided and $p$-values $<0.05$ were considered significant. Statistical analyses were performed using the software package SPSS 22.0 (SPSS Inc., Chicago, IL, United States of America).

\section{Results}

\section{Patient characteristics}

A total of 37 patients diagnosed with USC were included. The mean and mode age at time of diagnosis was 74 and 73 years, respectively (range $56-88$ years). The mean PFS was 14 months (range 0-96 months). A substantial number of patients were diagnosed in the early stages of the disease as $41 \%$ (15 of 37) and $8 \%$ (3 of 37) of the women presented with FIGO stage I and stage II, respectively. In $32 \%$ (12 of 37 ) of cases, the tumors were classified as stage III, while stage IV disease was diagnosed in 19\% (7 of 37) of cases. Primary debulking surgery was performed in all but one woman, who was regarded as inoperable due to advanced age, reduced performance status and advanced disease. Complete cytoreduction was achieved in $72 \%$ (26 of 36) of the women undergoing surgery, while optimal debulking could not be accomplished in $28 \%$ (10 of 36) of cases. $62 \%$ (23 of 37 ) of patients were additionally treated with adjuvant platinum-containing chemotherapy (Table 1). 
Table 1 Clinical-pathological characteristics of USC patients $(n=37)$

\begin{tabular}{ll}
\hline Clinical parameters & \\
\hline & mean (range) \\
Age at diagnosis; in years & $74(56-88)$ \\
Pollow-up time; in months & $35(2-113)$ \\
Progression-free interval; in months & $14(0-96)$ \\
IA & N (\%) \\
IB stage & \\
II & $5(14 \%)$ \\
IIIA & $10(27 \%)$ \\
IIIC & $3(8 \%)$ \\
IVA & $2(5 \%)$ \\
IVB & $10(27 \%)$ \\
Level of surgical cytoreduction ${ }^{a}$ & $1(3 \%)$ \\
Complete & $6(16 \%)$ \\
Residual disease & \\
Adjuvant chemotherapy & $26(72 \%)$ \\
Yes & $10(28 \%)$ \\
No &
\end{tabular}

Primary debulking surgery was performed on 36 out of 37 women

\section{mRNA expression patterns of $\mathrm{p} 53$ isoforms in USC}

We assessed the expression levels of total p53 mRNA, the C-terminal truncated isoforms $\mathrm{p} 53 \beta$ and $\mathrm{p} 53 \gamma$, and the $\mathrm{N}$-terminal truncated variants $\Delta 40 \mathrm{p} 53$ and $\Delta 133 \mathrm{p} 53$ by Real-Time qPCR. Notably, our assays were splice site specific, as such, combinations of alternative variants in the $\mathrm{C}$ - and N-terminal (variants with multiple alternative splice sites) were not discriminated. The $\Delta 133 \mathrm{p} 53$ variant was detected alone or in combination with other p53 isoforms in 97\% (36/37) of samples. The carboxy-terminal isoforms $\mathrm{p} 53 \beta$ and $\mathrm{p} 53 \gamma$ could be identified in $78 \%$ $(29 / 37)$ and $76 \%(28 / 37)$ of specimens, respectively. In our dataset, all but two samples that expressed p53 $\gamma$ also expressed $\mathrm{p} 53 \beta$. Moreover, in 25 of the samples in which $\mathrm{p} 53 \beta$ was detectable, p53 $\gamma$ was also expressed. A total of $70 \%(26 / 37)$ of samples expressed the combination of $\mathrm{p} 53 \beta$ and $\mathrm{p} 53 \gamma$ as well as $\Delta 133 \mathrm{p} 53$ mRNA. We were not able to detect expression of $\Delta 40 \mathrm{p} 53$ mRNA in any cases.(for illustration see Table 2).

The p53 isoform expression levels were found to vary considerably from patient to patient (Fig. 2a-d). The largest variability was observed for $\Delta 133 \mathrm{p} 53$, where we detected a 149-fold difference between the highest and the lowest expressing samples. The p $53 \beta$ and $\mathrm{p} 53 \gamma$ isoforms showed a variability of 109 -fold and 70-fold, respectively. While $\Delta 133$ p53 consistently accounted for the majority of isoforms expressed, p $53 \beta$ constituted a
Table 2 Overview over relative expression of p53 isoforms in individual patients together with progression free-survival

\begin{tabular}{|c|c|c|c|c|}
\hline Patient ID & $\Delta$ 133p53ratio & p53ßratio & p53yratio & $\begin{array}{l}\text { Progression free- } \\
\text { survival (months) }\end{array}$ \\
\hline 1 & 67.16 & 6.05 & .86 & 29 \\
\hline 2 & 19.17 & 4.90 & 0 & 0 \\
\hline 3 & 187.50 & 17.35 & 0 & 0 \\
\hline 4 & 19.87 & 0 & 0 & 14 \\
\hline 5 & 0 & 0 & 0 & 7 \\
\hline 6 & 17.21 & 0 & 0 & 1 \\
\hline 7 & 42.31 & 17.08 & 27.85 & 3 \\
\hline 8 & 234.46 & 0 & 0 & 14 \\
\hline 9 & 22.37 & 0 & 2.63 & 10 \\
\hline 10 & 5.16 & .79 & .57 & 5 \\
\hline 11 & 9.47 & 6.35 & 0 & 58 \\
\hline 12 & 7.93 & 1.68 & .29 & 96 \\
\hline 13 & 2.81 & .27 & .45 & 25 \\
\hline 14 & 2.65 & .67 & .66 & 11 \\
\hline 15 & 4.60 & 3.23 & 1.02 & 11 \\
\hline 16 & 6.78 & 3.60 & 1.35 & 2 \\
\hline 17 & 2.26 & 1.30 & .74 & 0 \\
\hline 18 & 5.75 & 2.10 & .93 & 2 \\
\hline 19 & 10.55 & 3.09 & 1.56 & 19 \\
\hline 20 & 28.51 & 1.48 & 2.14 & 0 \\
\hline 21 & 28.63 & 18.59 & 7.90 & 1 \\
\hline 22 & 19.20 & 2.52 & .54 & 31 \\
\hline 23 & 35.80 & 18.67 & 5.20 & 15 \\
\hline 24 & 33.33 & 2.89 & .34 & 43 \\
\hline 25 & 36.17 & 4.86 & 4.62 & 0 \\
\hline 26 & 97.55 & 60.37 & 3.39 & 0 \\
\hline 27 & 10.57 & 5.58 & 1.44 & 1 \\
\hline 28 & 6.16 & .98 & .48 & 4 \\
\hline 29 & 42.70 & 8.18 & 2.23 & 48 \\
\hline 30 & 10.28 & 4.42 & .61 & 28 \\
\hline 31 & 60.74 & 0 & 0 & 11 \\
\hline 32 & 38.58 & 5.87 & 2.71 & 0 \\
\hline 33 & 10.13 & 2.66 & 2.23 & 0 \\
\hline 34 & 85.68 & 0 & 0 & 11 \\
\hline 35 & 7.51 & 0 & 1.94 & 15 \\
\hline 36 & 25.74 & 7.85 & 1.64 & 6 \\
\hline 37 & 32.86 & 13.85 & 6.09 & 0 \\
\hline
\end{tabular}

maximum $4 \%$ of isoforms expressed, while p53y only was detectable in very low concentrations (Fig. 2e).

The mRNA expression levels of the p53 $\beta$, p $53 \gamma$, and $\Delta 133 p 53$ isoforms were all significantly associated with total p53 expression levels and each other (Fig. 3). We found that the total p53 expression levels correlated with 

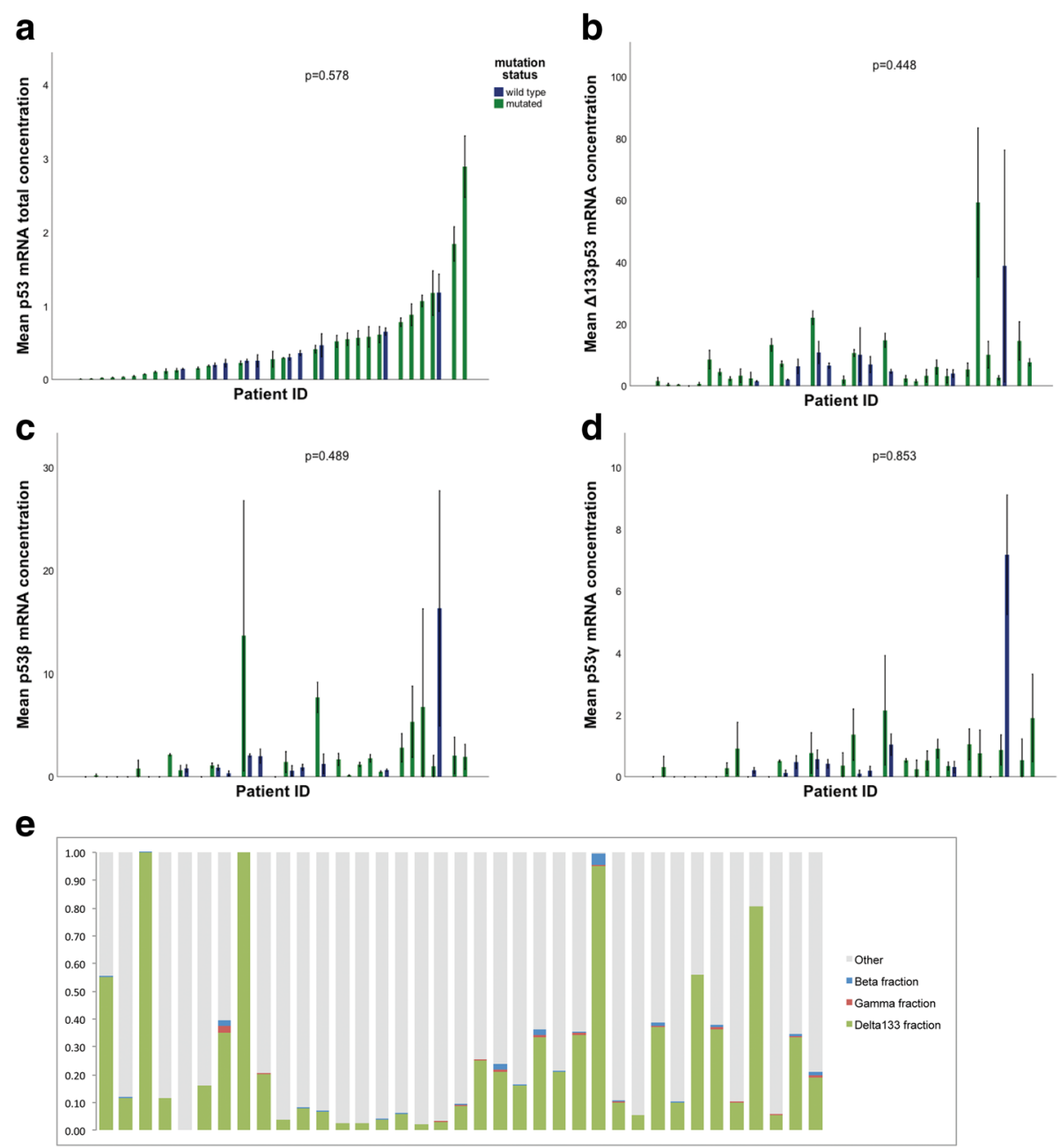

Fig. 2 mRNA expression levels of p53 isoforms in individual USC tumors. The green bars represent TP53 mutated specimens and the blue bars represent TP53 wild-type tumors. Non-significant differential distribution of mRNA expression, error bars represent $+/-1$ standard deviation in (a)

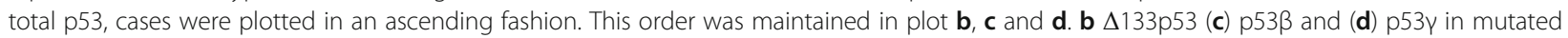
versus wild-type tumors. e Histogram displaying fractions of p53 isoforms to total p53 mRNA in individual specimens

the levels of $\Delta 133 \mathrm{p} 53(R=0.503, p=0.002), \mathrm{p} 53 \beta$ $(R=0.652, p<0.001)$ and $\mathrm{p} 53 \gamma(R=0.603, p<0.001)$ (Fig. $3 \mathrm{a}-\mathrm{c})$. In addition, the relative expression levels of $\mathrm{p} 53 \beta, \mathrm{p} 53 \gamma$ and $\Delta 133 \mathrm{p} 53$ isoforms within the tumors were highly correlated with one another. Expression of $\Delta 133 \mathrm{p} 53$ was significantly associated with p53 $\beta$ $(R=0.692, p<0.001)$ and p53y $(R=0.452, p=0.005)$. The p53 $\beta$ expression was linked with p53 $\gamma$ mRNA levels $(R=0.709, p<0.001)$ (Fig. $3 \mathrm{~d}-\mathrm{f})$.

\section{TP53 mutation status in USC}

In order to stratify p53 isoform expression data for TP53 mutational status, targeted sequencing was performed. We detected somatic mutations in the TP53 gene in 27 out of 37 (73\%) tumor samples (Table 3 ).
Notably, we found two of the samples to harbor two mutations. The most frequent point mutation detected was R248Q, observed in three patients. Several other hot-spot mutations such as $\mathrm{R} 175 \mathrm{H}$ and $\mathrm{R} 273 \mathrm{H}$, were observed. Total p53 expression levels $(p=0.578)$ as well as the splice variants $\Delta 133 \mathrm{p} 53(p=0.448), \mathrm{p} 53 \beta(p=0.489)$ and $\mathrm{p} 53 \gamma(p=0.853)$ were all independent of TP53 mutation status (Fig. 2a-d).

\section{Prediction of clinical features by $\mathrm{p} 53$ isoform expression} We tested whether the expression patterns of $\Delta 133 \mathrm{p} 53$, p $53 \beta$ and p53 $\gamma$ correlate with disease characteristics and identified a significant association between patient age and concentration of total p53 $(p=0.031)$. However, age was no longer significantly associated with expression of total p53 $(p=0.295)$ for multiple linear regression that 

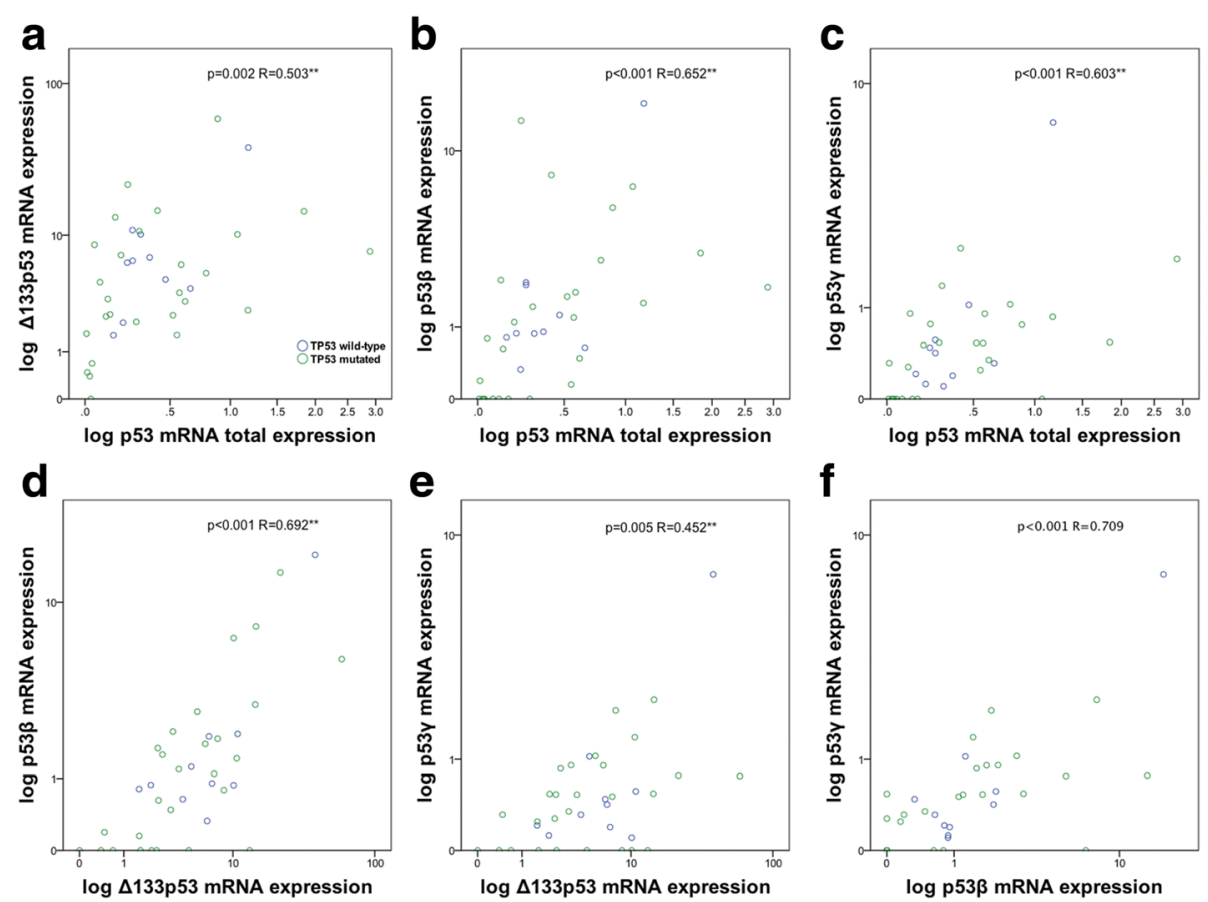

g

\begin{tabular}{|c|c|c|c|c|}
\hline \multicolumn{5}{|c|}{ p53 isoform expression correlations $-r$ and (p-values) } \\
\hline & total p53 & p53及 & p53y & $\mathbf{\Delta 1 3 3 p 5 3}$ \\
\hline total p53 & - & $\begin{array}{l}0.652^{* *} \\
(<0.001)\end{array}$ & $\begin{array}{l}0.603^{* *} \\
(<0.001)\end{array}$ & $\begin{array}{l}0.503^{* *} \\
(0.002)\end{array}$ \\
\hline p53ß & & . & $\begin{array}{c}0.709^{* *} \\
(<0.001)\end{array}$ & $\begin{array}{c}0.692^{* *} \\
(<0.001)\end{array}$ \\
\hline p53y & & & - & $\begin{array}{l}0.452^{* *} \\
(0.005)\end{array}$ \\
\hline$\Delta 133 p 53$ & & & & - \\
\hline
\end{tabular}

Fig. 3 Pair by pair scatter plots demonstrating mRNA expression levels in tumors. Tp53 mutated specimens are depicted in green color, while TP53 wild-type tumors are shown as blue dots. Expression of total p53 versus levels of (a) $\Delta 133 p 53$ (b) p53ß (c) p53y as well as expression of p53 isoforms among each other (d) $\Delta 133 \mathrm{p} 53$ to $\mathrm{p} 53 \beta$ (e) $\Delta 133 \mathrm{p} 53$ to $\mathrm{p} 53 \gamma$ (f) p53 $\mathrm{fo} \mathrm{p} 53 \gamma$. $\mathbf{g}$ Spearman correlation coefficients and $p$-values for univariate correlation of expression of total levels of p53 and levels of the individual p53 isoforms

introduced expression of the $\mathrm{p} 53 \beta, \mathrm{p} 53 \gamma$, and $\Delta 133 \mathrm{p} 53$ isoforms as covariates. For the other p53 splice variants, no relationship was established between mRNA expression levels and age or relevant tumor traits, such as stage at primary diagnosis and tumor resectability. Relative expression levels of the p53y isoform had an impact on time to relapse after primary treatment was completed. Our data showed that higher ratios of p53y to total p53 were associated with shorter PFS (log-rank $p=0.036)$ as illustrated in Fig. 4. No such correlation was found for the $\Delta 133 \mathrm{p} 53$ and $\mathrm{p} 53 \beta$ isoforms.

\section{Tp53 mutation status and clinical parameters}

Both the patient characteristics, such as age $(p=0.180)$ and the tumor features, such as FIGO stage at primary diagnosis $(p=0.271)$ and presence of complete cytoreduction in operated patients $(p=0.580)$, were independent of
TP53 mutation status. We found the mean PFS in patients with TP53 wild-type cancers to be 18 months versus 15 months among women with tumors harboring mutated TP53. However, this difference was not statistically significant $(\log -\operatorname{rank} p=0.399)$.

\section{Discussion}

Over the last decade, the description of splice variants of the TP53 gene has dynamically reformed the p53 field, and p53 isoforms have emerged as possible active contributors in cancer formation and progression [30] We have previously described that $\mathrm{p} 53 \beta$ and $\mathrm{p} 53 \gamma$ protein expression correlates positively with overall survival, chemotherapy response and mutational markers for survival in the aggressive blood cancer AML [24] Leukemia in general has a low occurrence of TP53 mutations. It was therefore interesting to examine whether the 
Table 3 Overview over TP53 mutations observed in patients

\begin{tabular}{|c|c|c|c|c|c|}
\hline Patient ID & FIGO 2009 tumor stage & Mutation $^{a}$ & Amino acid change & Effect & $\begin{array}{l}\text { Progression free } \\
\text { survival (months) }\end{array}$ \\
\hline 1 & 1c & $7577120 C>T$ & $\mathrm{R} 273 \mathrm{H}$ & missense $^{c}$ & 29 \\
\hline 2 & $4 b$ & 7577097C > T & D281N & missense $^{b}$ & 0 \\
\hline 3 & $4 b$ & $7577538 \mathrm{C}>\mathrm{T}$ & $\mathrm{R} 248 \mathrm{Q}$ & missense ${ }^{c}$ & 0 \\
\hline 4 & $1 b$ & $7577581 A>G$ & $\mathrm{Y} 234 \mathrm{H}$ & missense ${ }^{b}$ & 14 \\
\hline 5 & $3 c$ & $7,578,394 \mathrm{~T}>\mathrm{A}$ & $\mathrm{H} 179 \mathrm{~L}$ & missense $^{b}$ & 7 \\
\hline 6 & $2 b$ & $7577539 G>A$ & $\mathrm{R} 248 \mathrm{~W}$ & missense $e^{c}$ & 1 \\
\hline 7 & $3 c$ & $7578239 C>A$ & $\mathrm{E} 204^{\mathrm{a}}$ & nonsense ${ }^{b}$ & 3 \\
\hline 8 & $1 c$ & $7577120 \mathrm{C}>\mathrm{T}$ & $\mathrm{R} 273 \mathrm{H}$ & missense $^{c}$ & 14 \\
\hline \multirow[t]{2}{*}{9} & \multirow[t]{2}{*}{$1 a$} & $7577573 \mathrm{G}>\mathrm{T}$ & $Y 236^{\mathrm{a}}$ & nonsense $\mathrm{e}^{\mathrm{b}}$ & \multirow[t]{2}{*}{10} \\
\hline & & $7578211 C>A$ & R213L & missense $^{b}$ & \\
\hline 10 & $3 a$ & $7,577,580 \mathrm{~T}>\mathrm{C}$ & Y234C & missense $^{b}$ & 5 \\
\hline 11 & $4 \mathrm{~b}$ & $7577539 \mathrm{G}>\mathrm{A}$ & R248W & missense $^{c}$ & 58 \\
\hline 12 & $1 c$ & $7577153 C>A$ & G262 V & missense $^{b}$ & 96 \\
\hline 13 & $3 c$ & $7577538 \mathrm{C}>\mathrm{T}$ & $\mathrm{R} 248 \mathrm{Q}$ & missense $e^{c}$ & 25 \\
\hline 14 & $3 c$ & $7578508 \mathrm{C}>\mathrm{T}$ & C141Y & missense $^{\mathrm{b}}$ & 11 \\
\hline 15 & 1c & $7,578,442 \mathrm{~T}>\mathrm{C}$ & Y163C & missense $^{b}$ & 11 \\
\hline 16 & $3 c$ & $7578406 \mathrm{C}>\mathrm{T}$ & $\mathrm{R} 175 \mathrm{H}$ & missense $^{c}$ & 2 \\
\hline 17 & $4 b$ & 7577586A $>\mathrm{T}$ & I232N & missense $^{b}$ & 0 \\
\hline 18 & $3 c$ & $7577538 \mathrm{C}>\mathrm{T}$ & $\mathrm{R} 248 \mathrm{Q}$ & missense ${ }^{c}$ & 2 \\
\hline 19 & $1 a$ & $7578406 C>T$ & $\mathrm{R} 175 \mathrm{H}$ & missense $^{c}$ & 19 \\
\hline 21 & $2 a$ & 7579556ATCAA & & frameshift & 1 \\
\hline 23 & $1 b$ & $7577535 C>G$ & R249T & missense $^{\mathrm{b}}$ & 15 \\
\hline 25 & $4 a$ & $7578272 \mathrm{G}>\mathrm{A}$ & H193Y & missense ${ }^{b}$ & 0 \\
\hline 26 & $3 c$ & $7577121 \mathrm{G}>\mathrm{A}$ & $\mathrm{R} 273 \mathrm{C}$ & missense $^{b}$ & 0 \\
\hline 31 & $3 c$ & 7577569TGT & & non-frameshift deletion & 11 \\
\hline 32 & $3 c$ & $7,578,190 \mathrm{~T}>\mathrm{C}$ & Y220C & missense $^{b}$ & 0 \\
\hline 34 & $1 a$ & $7577141 C>T$ & G266E & missense ${ }^{b}$ & 11 \\
\hline \multirow[t]{2}{*}{35} & \multirow[t]{2}{*}{$3 a$} & $7577130 A>G$ & $F 270 L$ & missense $^{b}$ & \multirow[t]{2}{*}{15} \\
\hline & & $7577132 C>T$ & S269 N & partially functional ${ }^{b}$ & \\
\hline
\end{tabular}

${ }^{a}$ Coordinates; GRCh37

${ }^{\mathrm{b}}$ Mutation has been reported earlier in the IARC archive [33]

c Hot-spot mutation region

expression levels of $\mathrm{p} 53 \beta$, p53y, or other isoforms had a prognostic implication in tumors with a high frequency of TP53 mutations. A recent publication by Shen et al. showed not only that mRNA isoform variations are associated with clinical outcomes in TCGA breast cancer data, but also that alternative splicing-based survival predictors consistently outperform gene expression-based prognosticators [31].

The focus of the present study was to assess the role of p53 splice variants in USC in a well-defined cohort of patients by performing highly sensitive quantitative Real-Time PCR. We detected expression of p53 isoforms in $97 \%$ of cases and found that expression levels varied considerably from patient to patient. Specifically, we found that the expression levels of the p53 isoforms $\mathrm{p} 53 \beta$, p53 $\gamma$, and $\Delta 133 \mathrm{p} 53$ were all associated with total p53 expression levels. Whether this indicates that isoform expression is merely a side product of general TP53 transcriptional activity in many patients remains unknown. Furthermore we show that the relative expression of $\mathrm{p} 53 \beta, \mathrm{p} 53 \gamma$, and $\Delta 133 \mathrm{p} 53$ isoforms within the tumors were highly correlated with one another, consistent with findings in breast cancer [16].

The total $\Delta 133 \mathrm{p} 53$ levels constituted the majority of p53 isoforms expressed in USC, while the levels of p $53 \beta$ and p53y were much lower. The differential expression of $\Delta 133 p 53$ in cancerous cells seems to be highly dependent on the originating tissue. While an overexpression of 


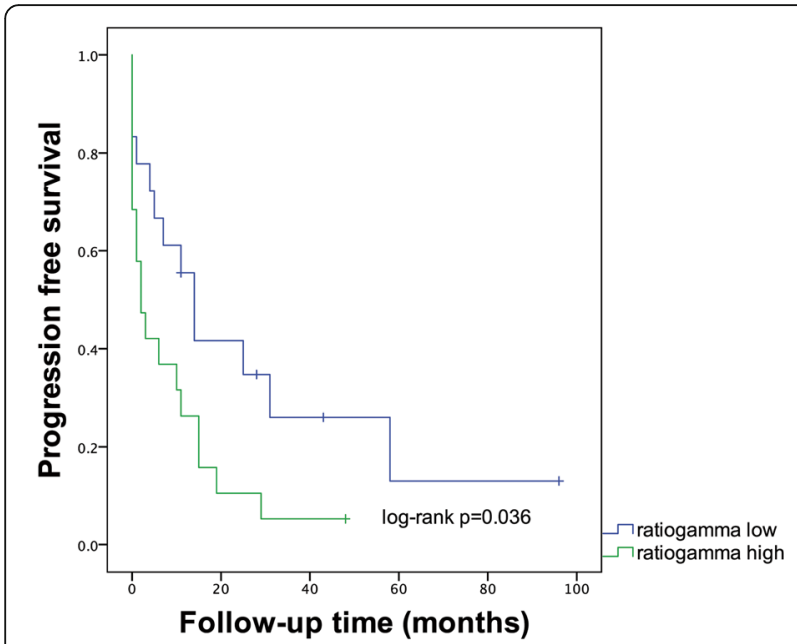

Fig. 4 Differential progression free survival in patients. Patients are grouped by median as expressing high p53 $\gamma$ relative to total p53 (ratiogammahigh) versus low $\mathrm{p} 53 \gamma$ relative to total p53 (ratiogammalow)

$\Delta 133$ p53 is seen in gastrointestinal tumors compared to cancer precursors [11] or paracancerous tissue [23], Van den Berg et al. showed that $\Delta 133$ p53 variants were downregulated in the early stages of clear cell renal carcinoma [22]. There are conflicting reports regarding the clinical impact of $\Delta 133 \mathrm{p} 53$ expression. The $\Delta 133 \mathrm{p} 53 \beta$-variant has recently been linked to increased tumor invasiveness and worse prognosis in a cohort of breast cancers [17], but higher $\Delta 133$ p53 levels have also been linked to favorable prognosis in TP53 mutant advanced ovarian cancer [19] No such clinical associations of $\Delta 133 \mathrm{p} 53$ expression were observed in our cohort.

We did not detect expression of the $\Delta 40 \mathrm{p} 53$ isoform in any of the patients. This finding contrasts with several other forms of cancer. In breast cancer, $\Delta 40 \mathrm{p} 53$ has been found to be the main isoform expressed, and it is significantly upregulated when compared to benign breast tissues, particularly in triple negative breast tumors [16] Hofstetter et al. showed the same significant upregulation of $\Delta 40 \mathrm{p} 53$ in mucinous ovarian carcinomas in contrast to normal ovarian tissues and also indicated that higher expression of $\Delta 40 \mathrm{p} 53$ constituted an independent prognosticator for longer PFS [20] In renal cell carcinoma, $\Delta 40 \mathrm{p} 53$ was also present and significantly upregulated in the advanced stages [22].

For the p53 $\beta$ isoform, Avery-Kiejda et al. [16] reported an association between lower expression levels and diminished metastasis-free survival and a significant negative association with tumor size in a series of breast cancers. In our data, no such effect was seen.

Although the number of patients included in our study is limited, our data strongly suggest that high relative expression of $\mathrm{p} 53 \mathrm{\gamma}$ is associated with shorter PFS. These findings are in contrast to data from breast cancer patients, where expression of $\mathrm{p} 53 \gamma$ has been linked to good prognosis in TP53 mutant tumors [15] and to tumor grade in unselected breast cancers [16]. In vitro, p53y has been shown to affect FLp53-dependent transactivation of Bax and is therefore believed to exert tumor-suppressive functions [10]. Furthermore, stable transfection of lung carcinoma cell lines with the p53 $\beta$ and $\mathrm{p} 53 \mathrm{\gamma}$ isoforms has been shown to exert chemosensitizing effects. Unexpectedly, the same cells showed accelerated tumor growth when compared to null cells in an in vivo model [32]. Although p53 $\gamma$ was associated with shorter PFS and we observed a strong correlation between levels of $\mathrm{p} 53 \gamma$ and $\mathrm{p} 53 \beta$, we could not establish an association between $\mathrm{p} 53 \beta$ and PFS.

Our data demonstrated that the TP53 mutation rate was $73 \%$, which is somewhat lower than in other studies [7]. This is probably due to random chance and the small cohort size. The number of patients with wild-type TP53 was limited in our present study, but we found no indications that the expression levels of any of the three detected isoforms were associated with TP53 mutation status in the tumors. This independence of isoform expression from TP53 mutation status is in line with previous findings in ovarian carcinoma and breast cancer series $[15,17,20]$. In our correlation analysis, TP53 mutation status could not predict cancer progression.

These data in combination highlight that p53 function is complex and must be regarded as a result of the precise and tissue-specific balance between expressions within the p53 isoform network [14]. It may well be, that the expression levels of certain isoforms may be associated with poor prognosis in some forms of cancer and good prognosis in others. Our data indicate that this may be the case for $\mathrm{p} 53 \gamma$. We believe that our findings can help direct further study of p53 isoform expression in USC by introducing a potential, clinically applicable biomarker for future validation in other cohorts.

\section{Conclusions}

The TP53 mutational profile by itself appears not to contain any prognostic information for patients in this cohort. This single-center study may offer some insight in the landscape of p53 isoform expression in USC and introduces $\mathrm{p} 53 \gamma$ as a possible predictor of progression freesurvival. The tissue-specific and complex regulation of the individual p53 isoforms must be understood before p53 isoforms can serve as predictive or prognostic biomarkers or therapeutic targets in USCs.

\section{Additional file}

Additional file 1: Table S1. Primers and probes for qPCR. (DOCX 14 kb) 


\section{Abbreviations}

AML: Acute myeloid leukemia; Bax: Bcl-2-associated X protein; CCNE1: Cyklin E1 Gene; C-terminal: Carboxy-terminal; FIGO: The International Federation of Gynecology and Obstetrics; MYC: MYC proto-oncogene; N-terminal: Aminoterminal; PFS: Progression-free survival; RECIST: Response evaluation criteria in solid tumors; RPLP2: Ribosomal protein lateral stalk subunit P2; RTqPCR: Quantitative real-time PCR; TCGA: The cancer genome atlas; TP53: Tumor protein p53; USC: Uterine serous carcinoma

\section{Acknowledgements}

We thank Britt Irene Edvardsen, Reidun Kopperud, Kadri Madissoo and Beryl Leirvaag for technical assistance.

\section{Funding}

This work was supported by grants from "The Western Norway regional Health Authority" (Project No. 911809 and 911852). The funding sources had no involvement in study design, collection of data, and analysis and interpretation of data. The writing of the report has not been influenced by the supporting institutions.

\section{Availability of data and materials}

The datasets used and/or analyzed during the current study are available from the corresponding author on reasonable request.

\section{Authors' contributions}

KB, SK, BTG and LB conceived experiments. KB and SK carried out experiments and analysed data. KB created figures. IS, JT, HMJW and KW helped with the acquisition of data. KB, SK, HMJW, BTG and LB conceived the study, participated in its design and coordination and wrote the manuscript. All authors were involved in writing the paper and had final approval of the submitted document.

\section{Ethics approval and consent to participate}

All parts of the study have been approved by the "Regional committee for Medical and Health research ethics West" REC VEST (Reference ID: 2009/2315). All participating patients provided written informed consent.

\section{Consent for publication}

Not applicable.

\section{Competing interests}

The authors declare that they have no competing interests.

\section{Publisher's Note}

Springer Nature remains neutral with regard to jurisdictional claims in published maps and institutional affiliations.

\footnotetext{
Author details

${ }^{1}$ Centre for Cancer Biomarkers (CCBIO), Department of Clinical Science, Precision Oncology Research Group, University of Bergen, Bergen, Norway. 2Department of Gynecology and Obstetrics, Haukeland University Hospital, N-5021 Bergen, Norway. ${ }^{3}$ Department of Oncology, Haukeland University Hospital, 5021 Bergen, Norway. ${ }^{4}$ Section of Oncology, Department of Clinical Science, University of Bergen, Bergen, Norway. ${ }^{5}$ Department of Pathology, Haukeland University Hospital, 5021 Bergen, Norway. ${ }^{6} \mathrm{CCBIO}$, Department of Clinical Medicine, Section for Pathology, University of Bergen, Bergen, Norway. ${ }^{7}$ Bergen Gynaecologic Cancer Research Group, Department of Clinical Medicine, University of Bergen, Bergen, Norway. ${ }^{8}$ Department of Internal Medicine, Haematology Section, Haukeland University Hospital, 5021 Bergen, Norway
}

Received: 4 September 2017 Accepted: 13 June 2018

Published online: 25 June 2018

\section{References}

1. Wright JD, Medel NIB, Sehouli J, Fujiwara K, Herzog TJ. Contemporary management of endometrial cancer. Lancet. 2012;379(9823):1352-60. https://doi.org/10.1016/S0140-6736(12)60442-5

2. Jemal A, Bray F, Center MM, Ferlay J, Ward E, Forman D. Global cancer statistics. CA Cancer J Clin. 2011;61(2):69-90. https://doi.org/10. 3322/caac.20107
3. Torre LA, Islami F, Siegel RL, Ward EM, Jemal A. Global cancer in women: burden and trends. Cancer Epidemiol Biomark Prev. 2017;26(4):444-57. https://doi.org/10.1158/1055-9965.EPI-16-0858.

4. Kurman RJ, Visvanathan K, Shih le M. Bokhman's dualistic model of endometrial carcinoma. Revisited. Gynecol Oncol. 2013;129(2):271-2. https:// doi.org/10.1016/j.ygyno.2013.03.029.

5. Black JD, English DP, Roque DM, Santin AD. Targeted therapy in uterine serous carcinoma: an aggressive variant of endometrial cancer. Women's Health. 2014;10(1):45-57. https://doi.org/10.2217/whe.13.72.

6. Goff BA. Uterine papillary serous carcinoma: what have we learned over the past quarter century? Gynecol Oncol. 2005;98(3):341-3. https://doi.org/10. 1016/j.ygyno.2005.07.006

7. Cancer Genome Atlas Research N. Integrated genomic characterization of endometrial carcinoma. Nature. 2013;497:67-73. https://doi.org/10.1038/ nature12113.

8. Meng X, Dizon DS, Yang S, Wang X, Zhu D, Thiel KW, Leslie KK. Strategies for molecularly enhanced chemotherapy to achieve synthetic lethality in endometrial tumors with mutant p53. Obstet Gynecol Int 2013; 2013: 828165. DOl: https://doi.org/10.1155/2013/828165.

9. Brosh $\mathrm{R}$, Rotter $\mathrm{V}$. When mutants gain new powers: news from the mutant p53 field. Nat Rev Cancer. 2009;9(10):701-13. https://doi.org/10. 1038/nrc2693.

10. Marcel V, Fernandes K, Terrier O, Lane DP, Bourdon JC. Modulation of p53beta and p53gamma expression by regulating the alternative splicing of TP53 gene modifies cellular response. Cell Death Differ. 2014;21(9):1377-87. https://doi.org/10.1038/cdd.2014.73.

11. Fujita K, Mondal AM, Horikawa I, Nguyen GH, Kumamoto K, Sohn J, Bowman ED, Mathe EA, Schetter AJ, Pine SR, Ji H, Vojtesek B, Bourdon JC, Lane DP, Harris CC. p53 isoforms Delta133p53 and p53beta are endogenous regulators of replicative cellular senescence. Nat Cell Biol. 2009;11(9):1135-42. https://doi.org/10.1038/ncb1928.

12. Scotti MM, Swanson MS. RNA mis-splicing in disease. Nat Rev Genet. 2016; 17(1):19-32. https://doi.org/10.1038/nrg.2015.3.

13. Sibley $C R$, Blazquez $L$, Ule J. Lessons from non-canonical splicing. Nat Rev Genet. 2016;17(7):407-21. https://doi.org/10.1038/nrg.2016.46.

14. Surget $\mathrm{S}$, Khoury MP, Bourdon JC. Uncovering the role of p53 splice variants in human malignancy: a clinical perspective. Onco Targets Ther. 2013;7:57-68. https://doi.org/10.2147/0TT.S53876.

15. Bourdon JC, Khoury MP, Diot A, Baker L, Fernandes K, Aoubala M, Quinlan P, Purdie CA, Jordan LB, Prats AC, Lane DP, Thompson AM. p53 mutant breast cancer patients expressing p53gamma have as good a prognosis as wildtype p53 breast cancer patients. Breast Cancer Res. 2011;13(1):R7. https://doi. org/10.1186/bcr2811.

16. Avery-Kiejda KA, Morten B, Wong-Brown MW, Mathe A, Scott RJ. The relative mRNA expression of p53 isoforms in breast cancer is associated with clinical features and outcome. Carcinogenesis. 2014;35(3):586-96. https://doi.org/10. 1093/carcin/bgt411.

17. Gadea G, Arsic N, Fernandes K, Diot A, Joruiz SM, Abdallah S, Meuray V, Vinot S, Anguille C, Remenyi J, Khoury MP, Quinlan PR, Purdie CA, Jordan LB, Fuller-Pace FV, de Toledo M, Cren M, Thompson AM, Bourdon JC, Roux P. TP53 drives invasion through expression of its Delta133p53beta variant. elife. 2016;5 https://doi.org/10.7554/eLife.14734.

18. Hofstetter G, Berger A, Fiegl H, Slade N, Zoric A, Holzer B, Schuster E, Mobus VJ, Reimer D, Daxenbichler G, Marth C, Zeimet AG, Concin N, Zeillinger R. Alternative splicing of p53 and p73: the novel p53 splice variant p53delta is an independent prognostic marker in ovarian cancer. Oncogene. 2010; 29(13):1997-2004. https://doi.org/10.1038/onc.2009.482.

19. Hofstetter G, Berger A, Schuster E, Wolf A, Hager G, Vergote I, Cadron I, Sehouli J, Braicu El, Mahner S, Speiser P, Marth C, Zeimet AG, Ulmer H, Zeillinger R, Concin N. Delta133p53 is an independent prognostic marker in p53 mutant advanced serous ovarian cancer. Br J Cancer. 2011;105(10): 1593-9. https://doi.org/10.1038/bjc.2011.433.

20. Hofstetter G, Berger A, Berger R, Zoric A, Braicu El, Reimer D, Fiegl H, Marth C, Zeimet AG, Ulmer $H$, Moll U, Zeillinger R, Concin N. The N-terminally truncated p53 isoform Delta40p53 influences prognosis in mucinous ovarian cancer. Int J Gynecol Cancer. 2012;22(3):372-9. https://doi.org/10. 1097/IGC.0b013e31823ca031.

21. Marabese M, Marchini S, Marrazzo E, Mariani P, Cattaneo D, Fossati R, Compagnoni A, Signorelli M, Moll UM, Codegoni AM, Broggini M. Expression levels of p53 and p73 isoforms in stage I and stage III ovarian cancer. Eur J Cancer. 2008;44(1):131-41. https://doi.org/10.1016/j.ejca.2007.10.011. 
22. van den Berg L, Segun AD, Mersch S, Blasberg N, Grinstein E, Wai D, Anlauf M, Gabbert HE, Mahotka C, Heikaus S. Regulation of p53 isoform expression in renal cell carcinoma. Front Biosci. 2010;2:1042-53. PMID: 20515774

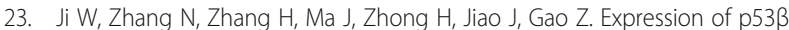
and $\Delta 133$ p53 isoforms in different gastric tissues. Int J Clin Exp Pathol. 2015; 8(9):10468-74. PMCID: PMC4637571

24. Anensen N, Hjelle SM, Van Belle W, Haaland I, Silden E, Bourdon JC, Hovland R, Tasken K, Knappskog S, Lonning PE, Bruserud O, Gjertsen BT. Correlation analysis of p53 protein isoforms with NPM1/FLT3 mutations and therapy response in acute myeloid leukemia. Oncogene. 2012;31(12):1533-45. https://doi.org/10.1038/onc.2011.348.

25. Edmondson RJ, Crosbie EJ, Nickkho-Amiry M, Kaufmann A, Stelloo E, Nijman HW, Leary A, Auguste A, Mileshkin L, Pollock P, Mackay HJ, Powell ME, Bosse T, Creutzberg $\mathrm{CL}$, Kitchener HC. Markers of the p53 pathway further refine molecular profiling in high-risk endometrial cancer: a TransPORTEC initiative. Gynecol Oncol. 2017;146(2):327-33. https://doi.org/10.1016/j.ygyno.2017.05.014.

26. Fransson A, Glaessgen D, Alfredsson J, Wiman KG, Bajalica-Lagercrantz S, Mohell N. Strong synergy with APR-246 and DNA-damaging drugs in primary cancer cells from patients with TP53 mutant high-grade serous ovarian cancer. J Ovarian Res. 2016;9(1):27. https://doi.org/10.1186/ s13048-016-0239-6.

27. Eisenhauer EA, Therasse P, Bogaerts J, Schwartz LH, Sargent D, Ford R, Dancey J, Arbuck S, Gwyther S, Mooney M, Rubinstein L, Shankar L, Dodd L, Kaplan R, Lacombe D, Verweij J. New response evaluation criteria in solid tumours: revised RECIST guideline (version 1.1). Eur J Cancer. 2009;45(2): 228-47. https://doi.org/10.1016/j.ejca.2008.10.026.

28. Stefansson IM, Raeder M, Wik E, Mannelqvist M, Kusonmano K, Knutsvik G, Haldorsen I, Trovik J, Øyan AM, Kalland KH, Staff AC, Salvesen HB, Akslen LA. Increased angiogenesis is associated with a 32-gene expression signature and 6p21 amplification in aggressive endometrial cancer. Oncotarget. 2015; 6(12):10634-45. https://doi.org/10.18632/oncotarget.3521.

29. Robinson JT, Thorvaldsdottir H, Winckler W, Guttman M, Lander ES, Getz G, Mesirov JP. Integrative genomics viewer. Nat Biotechnol. 2011;29(1):24-6. https://doi.org/10.1038/nbt.1754.

30. Mehta S, Tsai P, Lasham A, Campbell H, Reddel R, Braithwaite A, Print CA. Study of TP53 RNA splicing illustrates pitfalls of RNA-seq methodology. Cancer Res. 2016;76(24):7151-9.

31. Shen S, Wang Y, Wang C, Wu YN, Xing Y. SURVIV for survival analysis of mRNA isoform variation. Nat Commun. 2016;7:11548. https://doi.org/10. 1038/ncomms 11548 .

32. Silden E, Hjelle SM, Wergeland L, Sulen A, Andresen V, Bourdon JC, Micklem DR, McCormack E, Gjertsen BT. Expression of TP53 isoforms p53beta and p53gamma enhances chemosensitivity in TP53(null) cell lines. PLoS One. 2013;8(2):e56276. https://doi.org/10.1371/journal.pone.0056276.

33. Bouaoun L, Sonkin D, Ardin M, Hollstein M, Byrnes G, Zavadil J, Olivier M. TP53 variations in human cancers: new lessons from the IARC TP53 database and genomics data. Hum Mutat. 2016;37(9):865-7. https://doi.org/ 10.1002/humu.23035.

\section{Ready to submit your research? Choose BMC and benefit from:}

- fast, convenient online submission

- thorough peer review by experienced researchers in your field

- rapid publication on acceptance

- support for research data, including large and complex data types

- gold Open Access which fosters wider collaboration and increased citations - maximum visibility for your research: over $100 \mathrm{M}$ website views per year

At BMC, research is always in progress.

Learn more biomedcentral.com/submissions 